\title{
The variable clinical and CT findings after carotid occlusion: the role of collateral blood supply
}

\author{
M J G HARRISON, JOHN MARSHALL \\ From the Middlesex Hospital, and the Institute of Neurology, The National Hospital for Nervous Diseases, \\ London, UK
}

SUMMARY A retrospective review of 61 cases of angiographically confirmed occlusion of one or both carotid arteries was carried out to look at the evidence that the presence of collateral blood supply influenced the extent and type of cerebral infarction. Forty six patients had bilateral angiography from which it was possible to assess collateral filling of the internal carotid and middle cerebral arteries. As expected, patients with no CT scan evidence of infarction more frequently had transient ischaemic attacks or retinal infarcts than did those with visible cerebral infarcts. Patients with small cortical ischaemic lesions usually had appropriate neuropsychological or neurological deficits. Three patients with cortical watershed infarcts had a fluctuating deficit. Of the patients with bilateral angiograms $67 \%$ showed some filling via collaterals of the middle cerebral artery, and $43 \%$ of the internal carotid artery in the siphon. Those with collateral filling were mostly found to have normal CT scans or evidence of peripheral cortical lesions. By contrast most watershed and full territory infarcts were found in individuals whose angiograms showed no collateral filling. It is suggested that in many cases infarction occurs despite collateral flow and is due to distal embolism and that this may be relevant to the recently reported failure of the EC/IC bypass operation.

It has long been accepted that the effect of occlusion of the internal carotid artery can be highly variable. ${ }^{12}$ There may be massive infarction of the cerebral hemisphere with death from temporal lobe herniation, or the event may pass without clinical sequelae. Early reports stressed the importance of collateral blood supply and the variability of clinical outcome was attributed to the competence of the Circle of Willis ${ }^{3}$ and to atheromatous narrowing of cervical and intracranial arteries. ${ }^{4}$ A recent necropsy study ${ }^{5}$ has confirmed that the presence of collateral vessels is related to the site and size of cerebral infarction in subjects with carotid occlusion. The extent of collateral supply above the thrombosed carotid sinus is partly decided by the degree to which anterograde thrombus propagates into the carotid siphon and stem of the middle cerebral artery. ${ }^{6}$

Address for reprint requests: Dr M J G Harrison, The Middlesex Hospital, Mortimer Street, London WIN 8AA, UK.

Received 12 May 1987 and in revised form 21 September 1987. Accepted 22 September 1987
There is also evidence at both necropsy, ${ }^{6}$ and at angiography ${ }^{7}$ that embolism occurs above an occluded carotid artery into the stem of the middle cerebral or anterior cerebral arteries or to their branches.

The relative role of haemodynamic factors, the spread of occlusive thrombus and of embolism, is not clearly established. Most studies have been of necropsy material and thus biassed by fatal cases with large infarcts. The importance of understanding the pathophysiology of the variable cerebral ischaemic damage in response to carotid occlusion has been highlighted by the recent failure of the EC/IC bypass operation to prevent stroke in patients with a variety of occlusive cerebrovascular lesions including carotid occlusion. ${ }^{8}$

We considered that further information on the importance of collaterals to the extent of infarction might be obtained from a study of angiographic patterns. Only arterial studies provide sufficient resolution for this purpose but it is important to note that collateral routes demonstrated by selective vessel injections are only potential channels. No information can be derived on the actual volume of flow from the 
ophthalmic artery, the Circle of Willis or the contralateral carotid artery, though angiographic patterns show some correlation with PET scan evidence of impaired perfusion pressure. ${ }^{9}$

We have looked at the location, size and number of cerebral infarcts as judged by CT scanning, and at the evidence of collateral flow patterns as revealed by angiography in a series of 61 patients with occlusion of at least one carotid artery. The variable clinical picture was also studied for evidence of clinicoradiological correlations.

\section{Materials and methods}

Sixty one patients with angiographically confirmed occlusion of one or both internal carotid arteries were studied by retrospective review. The bilateral carotid angiograms in 46 cases also revealed whether there was evidence of development of a collateral supply via the ophthalmic artery or by cross filling through the Circle of Willis. In the other cases arch angiography or intravenous digital subtraction angiography had been employed.

The case notes were reviewed to determine the clinical presentation. The angiographic and CT findings were taken from the reports made at the time of the study by consultant neuroradiologists.

\section{Results}

\section{Clinical features}

Thirteen patients had had only one or more transient ischaemic attacks (TIAs). All the remainder had sustained a stroke though in 15 cases this was preceded by a TIA. Four patients had sustained a retinal infarct.

\section{CT scans}

All patients had been studied by computed tomography. In 13 patients the scans were entirely normal and in another seven only a mild degree of generalised atrophy was recorded. In 11 patients a small cortical lesion was seen often amounting to only an area of focal atrophy but believed to represent the effects of distal occlusion with limited cortical infarction. Twelve patients had multiple infarcts within the territory of the symptomatic occluded carotid artery. In 10 patients there was a single large infarct in the territory of the middle cerebral artery. In one instance the infarct also affected the territory of the anterior cerebral artery and in two others the posterior cerebral territory was included. One patient had a large infarct confined to the territory of the posterior cerebral artery. Four patients had deep low density lesions (terminal zone infarctions), ${ }^{10}$ and three had more superficial infarcts in classical watershed zones between the territories of the anterior and middle cerebral artery.

\section{Clinical and CT correlation}

Of the 20 patients whose CT scan showed no abnormality or only mild atrophy, 10 had had only a TIA and four a retinal infarct without cerebral symptoms. Two had had a focal cerebral episode lasting less than 3 weeks (reversible ischaemic neurological deficit, 0 RIND), and four a mild hemiparesis with or without sensory change. Of the 11 with a small cortical lesion all had had a RIND or completed stroke and 10 had $\underset{2}{2}$ cortical signs such as sensory inattention. In eight of these cases the lesion was parietal.

All of the four patients with a deep hemisphere infarct had had a completed stroke ${ }^{3}$ or RIND, though three had prior TIAs. In three cases the lesion was in $\frac{\bar{\omega}}{7}$ the capsule or globus pallidus, in one in the deep $\stackrel{\mathbb{Q}}{\Omega}$ frontal white matter.

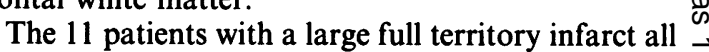
had completed major strokes. One had had a slow evolving onset and two had preceding TIAs. Of the $12 \overrightarrow{\vec{\omega}}$ with multiple infarcts three had TIAs only, seven TIAs going on to a RIND or completed stroke. In eight details of the symptomatology revealed that multiple sites were involved, and two others had mul- of tiple events even though the symptoms did not conclu sively prove that different sites were affected. All thres 0 patients with superficial watershed infarcts showed $\vec{\Phi}$ fluctuating deficit over the course of a few days, peto haps indicative of the haemodynamic nature of theif $\vec{T}$ pathophysiological process.

\section{Angiographic features}

There was a complete occlusion of the internal caroti artery at the bifurcation in 60 of the patients. In the remaining case the occlusion was at the skull base. None of the patients had clinical evidence of any cardiac disease that might have been a source of embolism though this had been suspected and sought especially in those with cortical or multiple infarcts. $\stackrel{\mathbb{Q}}{\complement}$ Not all had had echocardiography, however.

There was an adequate study of the contralateral $\stackrel{ }{\exists}$ carotid artery in 46 cases and this revealed stenosis of at least $50 \%$ or occlusion in $18(39 \%)$. Also in these cases it was possible to tell whether collateral flow had developed. Filling of the carotid siphon from the ophthalmic artery had been visible in 20 patients $(44 \%)$ ) but this provided collateral filling of the middle cerebral vessels in only $7(15 \%)$. Cross filling from the other side through the Circle of Willis was present in 25 of the 46 cases (54\%). Insufficient studies of the vertebral arteries had been carried out to report formally on the development of collaterals through the posterior part of the Circle of Willis, though at least two patients had filling of the middle cerebral $\sigma$ vessels from the posterior communicating artery. The $N$ filling of the symptomatic middle cerebral artery by 
Table Correlation of angiographic and CT findings in 46 cases of carotid occlusion

\begin{tabular}{lllll}
\hline & CT findings & & \\
\cline { 2 - 5 } Normal \\
Angiographic findings & $\begin{array}{l}\text { (or atrophy) } \\
(n=16)\end{array}$ & $\begin{array}{l}\text { Cortical infarct } \\
(\text { or multiple }) \\
(n=15)\end{array}$ & $\begin{array}{l}\text { Watershed lesions } \\
\text { (incl deep }) \\
(n=7)\end{array}$ & $\begin{array}{l}\text { Full territory infarct } \\
(n=8)\end{array}$ \\
\hline Filling IC & 8 & 10 & 0 & 2 \\
Filling MCA & 14 & 13 & 1 & 3 \\
\hline
\end{tabular}

collaterals was only rarely sufficiently complete to judge whether distal embolism had occurred. ${ }^{7}$

\section{Correlation of angiography and CT findings (table)}

In the 20 cases in which angiography showed collateral filling of the internal carotid artery the CT scans showed either no infarct (8) or peripheral cortical or multiple infarcts (10). Only two had large infarcts occupying the whole of the middle cerebral artery territory.

Patency of the stem of the middle cerebral artery with filling from the ophthalmic artery (seven cases) or from the Circle of Willis ( 25 cases) was seen in 31 instances. The scans in these patients showed no infarct in 14 and only peripheral cortical infarcts or multiple infarcts in 13. One subject had a deep hemisphere infarct and three had full middle cerebral artery territory lesions.

Thus most large infarcts ( 5 of 8 cases) had no visible middle cerebral artery filling. None of the three watershed infarct cases had middle cerebral artery opacification and only one of the four deeply sited infarcts did. By contrast 13 of 15 of those with peripheral infarcts showed middle cerebral artery filling, as did 14 of 16 of those whose CT scan showed no infarct.

\section{Discussion}

Fisher's classical studies ${ }^{1112}$ and those of earlier necropsy data ${ }^{1}$ revealed that the extent of cerebral infarction after carotid occlusion was enormously variable. The present clinical and radiological observations confirm this though it is important to stress that this was a selected group of cases with massive and fatal strokes under-represented. There were also no examples of the other end of the spectrum where complete carotid occlusion occurs without clinical accompaniment.

CT scanning revealed that $30 \%$ of the patients had no visible infarct and most of these patients had had only TIAs or retinal infarcts. Completed strokes or RINDs were experienced by most of those with CT scan evidence of infarction. In $17 \%$ of the group a small cortical infarct was revealed by scanning and these patients had appropriate neurological or neu- ropsychological deficits such as dysphasia or sensory inattention. By contrast $16 \%$ had full territory infarcts with major stroke deficit of hemiplegia and hemisensory loss.

The mechanism of infarction has been debated. The classical view is that the extent of infarction is dependent on the adequacy of the collateral circulation. Patients with no infarct are assumed to have sufficient perfusion via the external carotid artery or the Circle of Willis to prevent blood flow in the middle cerebral territory falling below the threshold for infarction though not necessarily below that for temporary symptoms. Patients with a large middle cerebral artery territory infarct are assumed to have poor collaterals either because propagation of the carotid thrombus has blocked collateral vessels or because congenital or atheromatous changes have interfered with their efficiency. Compensating dilatation of the collateral bed can be identified by a reduced capacity for further dilatation in response to carbon dioxide as measured in blood flow studies by $\mathrm{CO}_{2}$ reactivity, ${ }^{1314}$ or by the measurement of regionally elevated cerebral blood volume. ${ }^{9}$ Neither technique, however, had been employed in these retrospectively studied cases. The alternative mechanism for the production of focal cerebral infarction is distal embolism. EnsiedelLechtape $^{7}$ found evidence that such emboli might occur in as many as $50 \%$ of cases of recent occlusion of the carotid artery and that such emboli were usually distal in site in the branches of the middle cerebral artery. Barnett has pointed out that the distal stump of an occluded carotid can be the source of subsequent emboli causing symptoms. ${ }^{15}$

We sought evidence from the present study that might reveal how often an embolic mechanism operated and how often flow phenomena seemed more likely to be crucial. It is acknowledged that selective carotid angiography can only demonstrate the patency of potential collateral channels and does not measure quantitatively the flow through them.

There were few clinical clues to the mechanism of infarction ${ }^{16}$ though patients with watershed lesions had a fluctuating deficit compatible with a haemodynamic mechanism.

Of the 46 patients with bilateral angiograms twothirds showed some collateral filling of the middle 
cerebral artery. These cases mostly had normal CT scans or any infarcts were small and peripheral, and sometimes multiple. In these cases there is no evidence of spread of anterograde thrombus into the middle cerebral artery, collateral supply appears "adequate" and the infarcts are best explained by embolism.

In 25 cases the lack of filling of the intracranial internal carotid artery suggests that anterograde thrombus may well have spread to the level of the ophthalmic artery or beyond. These patients tended to have large full territory infarcts or watershed lesions or deep lesions. It is suggested that in these cases the lack of collateral has led to the large size or particular siting of the infarcts.

The rationale for the EC/IC bypass operation was essentially the provision of an improved collateral supply above a carotid occlusion. Perhaps its failure to affect the clinical course even in patients with bilateral carotid occlusion ${ }^{8}$ is to be explained by the evidence that collateral flow is not always crucial and embolism may frequently be the cause of infarction. Sixty seven per cent of the present series had angiographic evidence of collateral filling of the middle cerebral territory. Such patients might have little to gain from further artificial collateral supply, though proof would require regional measures of flow, metabolism and collateral reserve.

We are grateful to Dr R W Ross Russell and Miss B Laatz for help with this study.

\section{References}

1 Hultquist GT. Uber thrombosse und Embolie der Arteria carotis und hierbei vorkommande Gehernstorrungen. Jena. Gustav Fischer, 1942.

2 Zulch KJ, Gessage E. Infarcts in the carotid system. Vascular Surgery 1972;6:114-9.

3 Wiener LMR, Berry RG, Kundin J. Intracranial circulation in carotid occlusion. AMA Arch Neurol 1964;11:554-61.
4 Torvik A, Jorgensen L. Thrombotic and embolic occlusions of the carotid arteries in an autopsy series. Part 2 Cerebral lesions and clinical course. $J$ Neurol Sci 1966;3:410-32.

5 Rodda RA. The arterial patterns associated with internal carotid disease and cerebral infarcts. Stroke 1986;17:69-75.

6 Castaigne P, Lhermitte F, Gautier J-C, Escourolle R, Derouesné C. Internal carotid artery occlusion. A study of 61 instances in 50 patients with post mortem data. Brain 1970;93:231-58.

7 Einsiedel-Lechtape M. Embolic intracranial occlusions following complete internal carotid thrombosis. In: Meyer JS, Lechner M, Reivich M, ed. Cerebral Vascular Disease 2. Amsterdam: Excerpta Medica, 1979:325-30.

8 The EC/IC Bypass Study Group. Failure of extracranial intracranial arterial bypass to reduce the risk of ischemic stroke. $N$ Engl J Med 1985;313:1191-200.

9 Powers WJ, Press GA, Grubb RL, Gado M, Raichle ME. The effect of haemodynamically significant carotid artery disease on the haemodynamic status of the cerebral circulation. Ann Int Med 1987;106:27-35.

10 Ringelstein EB, Zeumer H, Angelou D. The pathogenesis of strokes from internal carotid artery occlusion. Diagnostic and therapeutic implications. Stroke 1983;14:867-75.

11 Fisher M. Occlusion of the internal carotid artery. $A M A$ Arch Neurol Psychiatr 1951;65:346-77.

12 Fisher M. Occlusion of the carotid arteries. AMA Arch Neurol Psychiatr 1954;72:187-204.

13 Norrving B, Nilsson B, Risberg J. rCBF in patients with carotid occlusion. Resting and hypercapnic flowo related to collateral pattern. Stroke 1982;13:155-62.

14 Brown MM, Wade JPD, Bishop CCR, Ross Russelle RW. Reactivity of the cerebral circulation in patients with carotid occlusion. J Neurol Neurosurg Psychiatry 1986;49:899-904.

15 Barnett HJM, Peerless SJ, Kaufman JCE. 'Stump' of internal carotid artery-A source for further embolic ischaemia. Stroke 1978;9:448-56.

16 Mitchinson MJ. The hypotensive stroke. Lancet 1980;i:244-6. 